\title{
The efficacy of interpersonal psychotherapy for depression among economically disadvantaged mothers
}

\author{
SHEREE L. TOTH, ${ }^{a}$ FRED A. ROGOSCH, ${ }^{a}$ ASSAF OSHRI, ${ }^{a}$ JULIE GRAVENER-DAVIS, ${ }^{a}$ ROBIN STURM, ${ }^{a}$ AND \\ ANTONIO ALEXANDER MORGAN-LÓPEZ ${ }^{b, c}$ \\ ${ }^{a}$ Mt. Hope Family Center, University of Rochester; ${ }^{b}$ University of North Carolina at Chapel Hill; and ${ }^{c}$ RTI International Research
}

\begin{abstract}
A randomized clinical trial was conducted to evaluate the efficacy of interpersonal psychotherapy (IPT) for ethnically and racially diverse, economically disadvantaged women with major depressive disorder. Non-treatment-seeking urban women $(N=128 ; M$ age $=25.40, S D=4.98)$ with infants were recruited from the community. Participants were at or below the poverty level: $59.4 \%$ were Black and $21.1 \%$ were Hispanic. Women were screened for depressive symptoms using the Center for Epidemiologic Studies Depression Scale; the Diagnostic Interview Schedule was used to confirm major depressive disorder diagnosis. Participants were randomized to individual IPT or enhanced community standard. Depressive symptoms were assessed before, after, and 8 months posttreatment with the Beck Depression Inventory-II and the Revised Hamilton Rating Scale for Depression. The Social Support Behaviors Scale, the Social Adjustment Scale-Self-Report, and the Perceived Stress Scale were administered to examine mediators of outcome at follow-up. Treatment effects were evaluated with a growth mixture model for randomized trials using complier-average causal effect estimation. Depressive symptoms trajectories from baseline through postintervention to follow-up showed significant decreases among the IPT group compared to the enhanced community standard group. Changes on the Perceived Stress Scale and the Social Support Behaviors Scale mediated sustained treatment outcome.
\end{abstract}

Major depressive disorder (MDD) is a significant public health problem that affects disproportionately more women than men (Kessler et al., 2003; Weissman \& Olfson, 1995). One in five women will experience at least one episode of depression during her lifetime, and the highest risk for initial onset of MDD is in women of childbearing years (Kessler, McGonagle, Swartz, Blazer, \& Nelson, 1993; Regier et al., 1988; Robins et al., 1984). High levels of depressive symptoms are particularly prevalent in minority women and economically disadvantaged women (Kessler et al., 1994, 2003; Segre, O'Hara, Arndt, \& Stuart, 2007; Williams \& Collins, 1995). However, minority status and vulnerability to depression may be because minority women are overrepresented among lower socioeconomic sectors. Poor White women have been found to have rates of depression similar to economically disadvantaged African American women (Hobfoll, Ritter, Lavin, Hulsizer, \& Cameron, 1995). Approximately $13 \%$ of mothers suffer from MDD during pregnancy or in the first year of their infant's life (O'Hara \& Swain, 1996), and rates of MDD as high as $25 \%$ have been

This research was supported by the National Institute of Mental Health, Grant MH091070. We thank the participants in this investigation, as well as the therapists and research assistants, including Brenda Ortolaza-Caraballo, Bree Scribner, and Deborah Welker. We thank Arin Connell for statistical consultation on the utilization of the complier average causal effect modeling on an earlier version of this manuscript.

Address correspondence and reprint requests to: Sheree L. Toth, Mt. Hope Family Center, University of Rochester, 187 Edinburgh Street, Rochester, NY 14608; E-mail: sheree.toth@ rochester.edu. found in economically disadvantaged mothers of young children (Miranda et al., 2003; Siefert, Bowman, Heflin, Danziger, \& Williams, 2000), highlighting the importance of targeting these women for intervention.

Unfortunately, despite the prevalence of depression in economically disadvantaged mothers, many do not seek treatment or receive treatments that are substandard and that fail to effectively alleviate their symptoms (Wang et al., 2005). An Institute of Medicine analysis of the quality of healthcare received by various racial and ethnic minority groups revealed consistent disparities and resultant worse outcomes of care for racial and ethnic minority populations (Smedley, Stith, $\&$ Nelson, 2002). In addition, minority individuals are less likely to seek and receive treatment than are White individuals, even after controlling for sociodemographic differences (US Department of Health \& Human Services, 2001). In a randomized clinical trial (RCT) with low-income young minority women, $83 \%$ of those referred for treatment for depression in the community did not attend even one session (Miranda et al., 2003). Findings such as these highlight the criticality of providing and evaluating interventions for MDD to ethnically and racially diverse economically disadvantaged mothers with young children and suggest that it may be beneficial to conduct screenings to identify these women in order to try to engage them in treatment.

Further underscoring the need for treatment in economically disadvantaged young mothers with MDD is the well-established connection between maternal depression and early symptoms of maladaptation in young offspring. Rates of 
secure attachment are often found to be lower in toddlers of mothers with MDD (Gravener et al., 2011; Martins \& Gaffan, 2000; Toth, Rogosch, Manly, \& Cicchetti, 2006). Maternal MDD and elevated depressive symptoms are also associated with higher levels of offspring behavior problems during childhood (Marchand, Hock, \& Widaman, 2002; Silk, Shaw, Forbes, Lane, \& Kovacs, 2006) and increased risk for depression, anxiety, and other major psychiatric disorders later in development (Hammen \& Brennan, 2003; Weissman, Wickramaratne, et al., 2006). Early behavior problems and difficulties navigating stage-salient tasks such as developing a secure attachment can initiate a negative developmental cascade in a young child (Masten \& Cicchetti, 2010). Timely intervention with young mothers with MDD may improve the developmental course not only for mothers themselves but also for their young children (Shaw, Connell, Dishion, Wilson, \& Gardner, 2009; Weissman, Pilowsky, et al., 2006). In addition, RCT intervention offers an excellent experimental opportunity to investigate the underlying mechanisms contributing to the development of psychopathology. Specifically, examination of the active ingredients that mediate the effect of the intervention on depression symptoms in a RCT context can shed light on the causal mechanisms that operate in the development of maternal depressotypic organization (Cicchetti \& Toth, 1998).

\section{Efficacious Treatments for MDD}

In addition to pharmacotherapy, a number of efficacious psychosocial interventions are available for MDD. Because many women prefer not to take medication for MDD during their childbearing years, the provision of alternative modes of psychotherapy is needed. Cognitive behavioral therapy and interpersonal psychotherapy (IPT) are two of the most widely investigated psychosocial treatments for MDD, and both have been found to be efficacious for treating MDD (i.e., Elkin et al., 1989; Hollon, DeRubeis, \& Seligman, 1992; Hollon \& Ponniah, 2010; Persons, Thase, \& Crits-Cristoph, 1996). Unfortunately, the majority of RCTs that have contributed to the evidence base for these interventions have been conducted with predominantly nonminority middle to upper socioeconomic status populations. Studies that formed the empirical base for the American Psychiatric Association guidelines for depression treatment included 3,860 participants, with only 27 identified as African American and none as being of Latina descent (US Department of Health and Human Services, 2001). Although the paucity of low-income and minority populations participating in clinical trials is beginning to change, considerably more research needs to be conducted on the efficacy of service delivery to racially and ethnically diverse low-income mothers with MDD.

We believe that IPT warrants further efficacy examination, particularly in economically disadvantaged and minority women, for a number of reasons. IPT is a well-established and efficacious treatment for depression (Cuijpers et al., 2011). It is well suited for impoverished mothers of infants because strengthening and expanding their relational network given possible social isolation may be particularly salient. The importance of providing social support is further highlighted by the strong association between poverty and single mother households (US Census Bureau, 2006-2010). The STAR*D depression treatment trial found that single women were less likely to remit compared to married or cohabitating women, suggesting the importance of social support for remission (Pilowsky et al., 2008; Trivedi et al., 2006) and further highlighting the need for a relational treatment for depression in a population with high rates of single mothers. Although cognitive behavior therapy is also an efficacious treatment for depression, it may be less efficacious when provided to populations with histories of trauma (Lewis et al., 2010). Thus, we chose to provide IPT in this clinical trial.

\section{IPT}

IPT is a manualized treatment that addresses symptoms associated with interpersonal aspects of depression (Klerman, Weissman, Rounsaville, \& Chevron, 1984; Stuart \& Robertson, 2003; Weissman, Markowitz, \& Klerman, 2000). The historical roots of IPT derive from the interpersonal school of psychiatry, and IPT is based on the empirical foundations of attachment theory, social roles, and life events (Stuart, 2008; Weissman et al., 2000). IPT has been evaluated for the treatment of acute depressive episodes, as well as for the prevention of major depression in controlled clinical trials (Weissman et al., 2000). Since its inception, it has been shown to be efficacious in several landmark psychotherapy trials, including the NIMH Treatment of Depression Collaborative Research Program and the Pittsburgh Maintenance Study of recurrent major depression (Elkin et al., 1989; Frank et al., 1990; Markowitz, 1998; Weissman \& Markowitz, 1994).

Investigations on the efficacy of IPT with low-income and minority populations are beginning to contribute to the evidence base of this model with diverse populations. In their work with primarily Hispanic adolescents, Mufson et al. found that the provision of IPT for adolescents resulted in significant decreases in MDD and other depressive disorders (Mufson et al., 1994, 2004; Mufson, Weissman, Moreau, \& Garfinkle, 1999). Similarly, IPT for adolescents has been found to be efficacious in reducing depressive symptoms in Latino adolescents (Rossello \& Bernal, 1999; Rossello, Bernal, \& Rivera-Medina, 2008). In addition, pilot research with a diverse sample suggests that IPT may be effective at reducing depression in women with significant trauma histories in a community health setting (Talbot et al., 2005).

Promising results on the efficacy of IPT for socioeconomically disadvantaged minority pregnant and perinatal women also have begun to emerge. In an investigation of group IPT for 48 non-treatment-seeking minority women, Krupnick et al. (2008) found that IPT was significantly more efficacious than a wait-list control condition in reducing posttraumatic stress disorder and depression symptom severity. A brief form of IPT also was found to be efficacious in decreasing 
depressive symptoms and preventing relapse in 25 low-income non-treatment-seeking pregnant women (Grote et al., 2009). Spinelli \& Endicott (2003) also found IPT to be effective in improving mood in 21 treatment-seeking women with antepartum depression relative to women receiving parenting education. Unfortunately, given relatively small sample sizes and attrition, the generalizability of these promising findings may be limited, and additional research with economically disadvantaged populations is necessary to contribute further to this emergent evidence base.

\section{Mediators of IPT}

Consistent with intervention outcome studies more generally, mediators of IPT efficacy have rarely been identified. Ideally, clinical trials should be conceptualized, designed, and evaluated in ways that enable their results to enhance the understanding of pathways that contribute to efficacy (Kazdin, 2007; Kraemer, Wilson, Fairburn, \& Agras, 2002). Therefore, the identification of mediational processes for IPT addresses a significant gap in the literature. The importance of preselecting potential mediator variables within a solid theoretical context has been highlighted (Kraemer et al., 2002). Although minimal research has been conducted on the mechanisms through which IPT works, the theoretical underpinnings of the model highlight variables that might be expected to contribute to positive outcomes. IPT's interpersonal orientation, with a focus on improving the patient's ability to cope with, adapt to, and improve her social environment (Stuart \& Robertson, 2003), suggests the importance of evaluating social relationship variables. In addition, the use of problem solving as a primary therapeutic technique in IPT (Stuart \& Robertson, 2003) suggests that change may occur through alleviating stress levels as individuals learn to accurately understand their problems and generate, evaluate, and enact solutions. Such techniques may serve to create a sense of self-efficacy and control, potentially decreasing levels of stress in interpersonal and other areas of a patient's life. Accordingly, perceived stress was chosen as an additional candidate for mediation.

The purpose of the current investigation was to conduct an RCT evaluating the efficacy of IPT for ethnically and racially diverse economically disadvantaged mothers with MDD. Given the reluctance of many minority women to seek treatment as discussed above, we sought to identify low-income ethnically and racially diverse mothers of infants by conducting screenings for depression in community settings. We hypothesized that women with MDD who received IPT compared with women in the enhanced community standard (ECS) group would evidence a decrease in depressive symptoms following treatment. We further hypothesized that posttreatment gains would be maintained 8 months later. Given the focus of IPT on the interpersonal context with the goal of reducing depressive symptoms, we expected that perceived increases in social supports, improved social adjustment, and decreased perceived stress would mediate sustained treatment outcome.

\section{Method}

\section{Participants}

Participants included 128 low-income urban women (aged 18-40) with a 12-month-old infant. Mothers were targeted because women with infants are at particularly high risk for depression (Vesga-Lopez et al., 2008). The current investigation focused on maternal depression and is the first report to emerge from a larger investigation of the effects of treatment for maternal depression on offspring outcomes. Mothers provided informed consent for participation prior to the initiation of data collection, and the research was conducted in accord with the institutional review board approval. All women met criteria for MDD. We recruited a community sample of nontreatment-seeking women from primary care clinics serving low-income women and from Women, Infant, and Children clinics. To be eligible, women needed to reside at or below the federal poverty level. Seventy-eight percent of the sample was below the US Department of Health and Human Services definition of poverty level, and 96\% met Women, Infant, and Children criteria ( $185 \%$ of the poverty level). A project recruitment coordinator initially screened women with the Center for Epidemiologic Studies Depression Scale (CES-D; Radloff, 1977), and those scoring above 16 were targeted for further assessments to determine eligibility for inclusion. Women who subsequently scored 19 or higher on the Beck Depression Inventory-II (BDI-II; Beck, Steer, \& Brown, 1996), and who met MDD diagnostic criteria based on the operational criteria on the Diagnostic Interview Schedule for DSM-IV (DIS-IV; Robins, Cottler, Bucholz, \& Compton, 1995) were eligible to participate.

For all but $6.3 \%$ of the women, the onset of their first major depressive episode had been over 1 year ago, thus preceding the infant's birth. Accordingly, the current sample did not comprise women with depression restricted to the postpartum period, but rather was of longer standing duration. In terms of comorbid DSM-IV diagnoses: $50 \%, 33.6 \%$, and $16.4 \%$ of participants met diagnoses for an anxiety disorder (non posttraumatic stress disorder), posttraumatic stress disorder, and antisocial personality disorder, respectively; $21.8 \%$ were comorbid for anxiety and posttraumatic stress disorder diagnoses. No significant statistical differences were found in rate of comorbid disorders between the treatment and the ECS groups.

Although scores on the Revised Hamilton Rating Scale for Depression (HRSD-R) of 14 or higher are generally considered to denote the presence of MDD, utilization of this cutoff criteria for study admission has been criticized because individuals may be erroneously excluded (Bagby, Ryder, Schuller, \& Marshall, 2004; Morris et al., 2007). Therefore, the HRSD-R was not used to exclude participants in the current investigation. Consistent with inclusion criteria, at baseline all depressed women had BDI-II scores above 19 and met criteria for an MDD. Women meeting diagnostic criteria for lifetime bipolar disorder or for any lifetime psychotic spectrum 
disorder were excluded. Women with mood disorder due to a general medical condition and substance-induced mood disorder were also excluded, as were women with any current alcohol or substance abuse disorder as defined by DSM-IV criteria. Women with other comorbid disorders were not excluded.

\section{Procedures}

All assessments were conducted by trained interviewers who were unaware of group condition or study hypotheses. The HRSD-R was completed by trained clinicians who were not the providers of treatment in this investigation. Because of possible variations in literacy and reading ability, all self-report measures were read to participants while they followed along and marked their answers. Following confirmation of diagnostic status, women were randomized to the IPT or to the ECS group, using a progressive block randomization procedure over the extended period of participant recruitment. Demographic variables including age, race, ethnicity, education, and number of children were used as blocking variables. Because the clinical trial involved women who were not seeking treatment, we expected that there would be a moderate number of participants who would not be interested in the active IPT arm when offered and thus would decline treatment, thereby not complying with their random assignment to receive the intervention (Little \& Yau, 1998). Accordingly, the ratio of random assignment to IPT versus ECS was adjusted over time in order to ensure that sufficient numbers of women would receive IPT, the active intervention under evaluation. Thus, more women were randomized to receive IPT $(n=99)$ than the ECS condition $(n=29)$. Group assignment was not revealed until completion of the baseline research assessments, at which time participants were informed of their group assignment by the recruitment coordinator.

Recruitment and baseline assessments occurred between April 8, 2004, and June 10, 2008. The research assessments were repeated at postintervention, conducted between September 30, 2004, and February 16, 2009, and again subsequently for an 8-month postintervention follow-up assessment (February 15, 2005, to June 14, 2009).

\section{Intervention groups}

IPT. IPT was delivered in accord with the treatment manual (Weissman et al., 2000) and included the provision of 14 1-hr sessions on a weekly basis. The mean number of sessions completed was 13.68 , with $84 \%$ of participants completing all 14 sessions. Although traditionally provided in clinic settings, flexibility of delivery site (home vs. clinic) was offered to reduce the possible stigma associated with receiving mental health services for low-income racially and ethnically diverse participants and to increase receptivity to services. Depression was explained as common feelings that can be associated with the many challenges parents face with childrearing. At times, language focused more on "feeling over- whelmed, stressed, and down" because it was difficult for some clients to acknowledge feeling "depressed." Therefore, psychoeducation around depression that therapists typically provide in the initial phase sometimes was provided later in treatment once therapeutic rapport was stronger. Therapists included master's or doctoral level practitioners who were trained in IPT in accord with credentialing recommendations. Therapists had a minimum of 10 years of experience with the provision of psychotherapy to low-income populations and at least 2 years of supervised experience in the provision of IPT. Weekly individual and group supervision was provided by supervisors who also met credentialing requirements for the supervisory level. Fidelity was monitored through the completion of therapist questionnaires at the initial, intermediate, and termination phases of IPT. The questionnaires, which were reviewed by supervisors, included information on sessions held, as well as therapists' evaluations of the extent of progress on client goals. One audiotape from each of the initial (Sessions 1-3), intermediate (Sessions 4-11), and termination (Sessions 12-14) phases for each client was randomly selected to be reviewed by an individual who had been trained to meet credentialing criteria established for IPT supervisors and who was not providing treatment to participants in order to ensure treatment fidelity. A standard rating scale (available upon request) was developed and utilized to rate the tapes. Supervisors were alerted if any departure from the treatment protocol was identified.

$E C S$. Because it is not ethical to withhold treatment from women who have been identified as depressed, women not randomized to IPT were actively offered referral to services typically available in the community. However, these women were not required to be in treatment unless they chose to do so. Overall, $66.5 \%$ elected to be involved in treatment for depression, and all of these women received individual counseling or psychotherapy. In this subgroup participating in treatment, additional interventions also were received, including medication (52.6\%), support groups $(42.1 \%)$, family/marital counseling $(10.5 \%)$, and day treatment $(21.1 \%)$. All women in the ECS group also had access to a project staff member who provided periodic informational newsletters, basic education about MDD, support, and referrals to community mental health centers to assist them with accessing treatment, as requested. The staff member was very active in referring ECS participants to treatment and, if needed, would assist them in attending their initial intake appointments, be available for support, or follow-up with phone calls to ascertain how treatment was proceeding. Thus, treatment received in the ECS group varied from no active intervention to psychotherapy plus additional services.

\section{Measures}

CES-D. The CES-D (Radloff, 1977) is a frequently used, well-validated 20-item scale to screen for depression. Scores of $>16$ predict a high likelihood of MDD. 
DIS-IV. The DIS-IV (Robins et al., 1995) is a structured interview designed to assess diagnostic criteria for Axis I disorders, as well as for antisocial personality disorder, as outlined in DSM-IV (American Psychiatric Association, 1994). The DIS-IV ascertains diagnoses present in the past year, the past 6 months, and those that are current or remitted. The DIS has been shown to be reliable and valid for use in psychiatric epidemiological field studies (Robins, Helzer, Croughan, \& Ratcliff, 1981; Robins, Helzer, Ratcliff, \& Seyfried, 1982). Robins et al. (1981) compared DSM diagnoses made using the DIS to those made by psychiatrists and reported mean $\kappa$ of 0.69 , sensitivity of $75 \%$, and specificity of $94 \%$. Given the forced choice structured format of the DIS, interviewers do not need to be trained clinicians. All interviewers were trained to criterion reliability in the administration of the DIS, and computer-generated diagnoses were utilized.

BDI-II. The BDI-II (Beck, Steer, \& Brown, 1996) is the most widely used self-report instrument for measuring the severity of depression. It includes 21 questions in a multiple-choice format, and scores of 17 or above indicate levels of depression with clinical significance. Previous studies report that the BDI-II demonstrates good internal consistency $(\alpha=0.91)$ and validity (Dozois, Dobson \& Ahnberg 1998; Storch, Roberti, \& Roth, 2004). In the current study, the average internal consistency of the BDI-II based on the three assessments was $\alpha=0.94$.

$H R S D-R$. The HRSD-R (Warren, 1994) is a widely used instrument to evaluate depression and treatment response in adult clinical populations. Based on clinical interview, it assesses the range of depressive symptoms (psychoaffective and somatic) and their severity. Scores range from 0 to 54, and scores in the 17 to 25 range are characterized as experiencing MDD, with scores above 25 indicting severe depression. A cutoff score of 14 has been used to distinguish depressed from nondepressed individuals (Khan, Schwartz, Kolts, Ridgway, \& Lineberry, 2007; Leentjens, Verhey, Lousberg, Spitsbergen, \& Wilmink, 2000). A recent review of studies using the 17-item HRSD-R reported a mean coefficient $\alpha=0.81$, supporting the reliability of the scale (Lopez-Pina, SanchezMeca, \& Rosa-Alcazar, 2009). Excellent interrater reliability (0.93-0.99) has also been reported for the total score (Tabuse et al., 2007). The HRSD-R demonstrated very good reliability in the current study (average $\alpha=0.85$ ), and all tapes also were reviewed by the project coordinator.

Perceived Stress Scale (PSS). The PSS (Cohen, Kamarck, \& Mermelstein, 1983) is a self-report measure of perceived stress. It is a psychometrically sound 14-item questionnaire that measures the degree to which respondents feel their lives are unpredictable, uncontrollable, and overwhelming. Previous research with this measure has reported high internal consistency (Cronbach $\alpha=0.91$ ), concurrent validity with a measure of mental health, and convergent validity with the Posttraumatic Stress-Arousal Symptoms Scale (Mitchell,
Crane, \& Kim, 2008). Test-retest reliability has been reported to range from 0.85 to 0.55 for a 2-day and a 6-week period, respectively (Cohen et al., 1983). The PSS has also been found to be correlated with depression and with physical symptoms (e.g., Cohen et al., 1983; Whiffen \& Gotlib, 1993). The reliability score of the PSS based on the three assessments was $\alpha=0.84$.

Social Support Behaviors Scale (SSB). The SSB (Vaux, Riedel, \& Stewart 1987) is a 45-item instrument measuring real and potential social supports available to individuals. Five modes are assessed, including emotional, socializing, practical assistance, financial assistance, and advice/guidance. Separate scales assess these forms of support for family and for friends. Internal consistencies for the scales have exceeded $\alpha=0.80$ (Vaux et al., 1987). Concurrent validity has been demonstrated through high correlations with social support network associations, support appraisals, and the Inventory of Socially Supportive Behaviors (Vaux \& Harrison, 1985; Vaux et al., 1987). The average reliability scores across the three assessments were excellent (SSB family, $\alpha=0.97$; SSB friends, $\alpha=0.97$ ).

Social Adjustment Scale-Self-Report (SAS-SR). The SASSR (Weissman, 1999) evaluates functioning in six role areas, including work, social and leisure activities, relationships with extended family, role as a marital partner, parental role, and role within the family unit. Instrumental and expressive features of functioning within these roles are assessed. The 54-item instrument yields seven scores, including functioning in each of the six roles and a total score. The measure has been used extensively in studies of treatments for mental disorders (Bateman \& Fonagy, 1999; Grote et al., 2009; Gunlicks-Stoessel, Mufson, Jekal, \& Turner, 2010; Lenze et al., 2002), and research has demonstrated a high correlation (0.72) between interview ratings of overall adjustment and the SAS-SR (Weissman \& Bothwell, 1976). The average SAS-R internal consistency in the current study based on the three time assessments was $\alpha=0.80$.

Childhood Trauma Questionnaire (CTQ). The CTQ (Bernstein et al., 2003) is a 28-item self-report assessment that measures retrospective accounts of childhood maltreatment. Participants are presented with statements reflecting childhood experiences that occurred before the age of 18 and are asked to rate items on a 5-point Likert scale ranging from never true to very often true. The five domains assessed include emotional abuse, physical abuse, sexual abuse, emotional neglect, and physical neglect. Bernstein and Fink (1994) reported moderately high internal consistency (Cronbach $\alpha=0.66$ 0.92 ) and test-retest reliability (Cronbach $\alpha=0.79-0.86$ ). The CTQ demonstrates good convergent validity with other self-report and interview measures of child maltreatment (Bernstein et al., 2003; Hyman, Garcia, Kemp, Mazure, \& Sinha, 2005). The internal consistency of the CTQ measured at baseline was $\alpha=0.76$. 


\section{Analytic plan}

We tested differences in demographic, depression, and trauma variables between women randomly assigned to the IPT and the ECS groups using chi-square and analysis of variance. We conducted analyses of overall treatment effects and subsequent mediational processes under the complier average causal effect (CACE) modeling framework within Mplus Version 6 (Muthén \& Muthén, 1998-2010). We used the robust maximum likelihood (Yuan \& Bentler, 2000) estimator in all analyses involving a structural equation mixture modeling framework (e.g., CACE modeling and mediation models) under the assumption that missingness was related to variables that were observed but unrelated to the missing values themselves (i.e., missing at random; Schafer \& Graham, 2002); no variable had a rate of missingness greater than $6.25 \%$.

CACE modeling. We employed CACE modeling because of the proportion of participants who were randomly assigned to the IPT condition but who failed to reach a sufficient level of treatment engagement (i.e., fewer than three sessions), as is common in randomized encouragement trial designs (Connell, 2009). Although other analysis approaches and frameworks exist for addressing noncompliance (e.g., per protocol analysis, as-treated analysis, intent to treat [ITT] analysis), each may lead to bias in treatment effect parameter estimates relative to what the true causal effect of receiving treatment would have been in the population (Jo, 2002). The more commonly utilized framework among these options is ITT analysis. ITT retains all participants who were randomized to treatment in the treatment group, regardless of whether they received any dosage of the treatment. This leads to bias with regard to causal effect parameter estimates because participants who received the full treatment are treated as equivalent to participants who refused the treatment. Accordingly, the treatment effect estimate in this case is referred to as the "average causal effect of treatment as treatment was assigned" but not as treatment was actually received (Jo, 2002, p. 180). If the researcher is more interested in the effect of treatment assignment, ITT is an appropriate analysis as long as (a) the outcomes that would have been observed had the person been assigned to the other condition are unrelated to the values observed among people in that other condition (the stable treatment unit value assumption); and (b) randomization was successful.

CACE estimation jointly models the impact of treatment assignment and treatment receipt and focuses on the treatment effect when treatment is actually received (Connell, 2009; Jo, 2002, 2008a, 2008b; Little \& Yau, 1998). The CACE estimate can be expressed as the following:

$$
\mathrm{CACE}=\beta_{\text {Treatment Compliers }}-\beta_{\text {Control Compliers }},
$$

where $\beta_{\text {Treatment Compliers }}$ is the mean growth rate over time on the outcome for compliers in the active treatment condition and $\beta_{\text {Control Compliers }}$ is the mean growth rate over time on the outcome for compliers in the control condition under the assumption that the two requirements noted above for ITT (stable treatment unit value assumption and random assignment) hold. However, compliance with the treatment can never be observed in the control condition precisely because control participants never have the opportunity to refuse the active treatment; hence, $\beta_{\text {Control Compliers }}$ cannot be directly estimated. All that is available in the data is the overall mean rate of change over time in the control group (i.e., $\beta_{\text {Control }}$ ), but in theory $\beta_{\text {Control }}$ is made up of the following components:

$$
\begin{aligned}
\beta_{\text {Control }}= & \pi_{\text {Compliers }} \beta_{\text {Control Compliers }} \\
& +\pi_{\text {Noncompliers }} \beta_{\text {Control Noncompliers }},
\end{aligned}
$$

where $\pi_{\text {Compliers }}$ is the proportion of compliers and $\pi_{\text {Noncompliers }}$ is the proportion of noncompliers. Here, the compliance rate in the treatment condition is used in place of the missing value in the control condition because it is assumed that the compliance rate is the same across the treatment and the control conditions due to randomization. However, it is only observable in the treatment condition. Under additional assumptions (i.e., there are no participants who decline whichever condition they were assigned, treatment assignment in and of itself has no effect among noncompliers, and compliance rate must be greater than zero), the CACE estimate can be reexpressed in terms of the observed data (Jo, 2002, p.182) as simply the ITT treatment effect parameter divided by the compliance proportion:

$$
\text { CACE }=\left(\beta_{\text {Treatment }}-\beta_{\text {Control }}\right) / \pi_{\text {Compliers }} .
$$

Note that this estimate would not be the same as simply excluding noncompliers from the analysis (e.g., per protocol analysis) because the compliance rate would not be incorporated into the analysis. The analysis also can include covariates that (a) predict compliance and adjust the estimated compliance rates and (b) account for variation among growth parameters.

Mediation analysis in CACE. To assess indirect effects of IPT on depressive symptomatology, mediation effects of stress, social support, and social adjustment were tested in the CACE analysis framework using the approach that combines longitudinal growth modeling with mediation (Cheong, MacKinnon \& Khoo, 2001, 2003) and CACE-adjusted mediation effects (Jo, 2008b). A series of CACE models were estimated to assess whether IPT influenced depressive symptomatology at the 8-month follow-up (i.e., the random intercept set at the 8-month follow-up, controlling for changes over time from baseline through to the 8-month follow-up) indirectly through changes over time in four mediators (PSS, SSB-family, SSB-friends, and SAS-SR). Estimates for paths from the IPT condition indicator to the mediator slope(s) and from the mediator slope(s) to the depression intercept at 8 months postintervention were assessed for signif- 
icance. If each effect was significant, then the estimates, the standard errors, and the correlation between mediation effect parameter estimates (if they were nonzero; MacKinnon, 2008, chap. 7) were used to test for mediation within the compliers class using the empirical Asymmetric Confidence Interval Test within the R-Mediation statistical package (Tofighi \& MacKinnon, 2011).

\section{Results}

Table 1 provides a comparison between the IPT and the ECS groups, as assigned at baseline, on a range of demographic variables including marital status, maternal education, child gender, maternal race/ethnicity, and total income. No statistically significant between-group differences were observed. Similarly, baseline differences on depression measures (i.e., HRSD-II and BDI-II) were nonsignificant. In addition, given the high-risk nature of the targeted families, participants were compared at baseline on their level of self-reported childhood maltreatment and trauma experiences. Univariate analyses of variance and chi-square analyses confirmed no significant differences at baseline between the IPT and the ECS groups on child maltreatment cutoff score and on mean rate of trauma experiences among the mothers. The whole sample presented with extensive histories of maltreatment as assessed by the CTQ, as well as with elevated endorsement of trauma experiences on the DIS-IV. For example, 38\% reported having been mugged or threatened, $30 \%$ reported having been raped or sexually assaulted by a relative, and $53.9 \%$ reported having seen someone being seriously injured or killed.

\section{CACE analysis}

An initial recommended step in CACE analysis is to define participant "engagement" in treatment (Connell, 2009). We adopted a stringent definition of engagement whereby attending at least 12 sessions was defined as "compliance," whereas attending 0-3 sessions was defined as "noncompliance" because of minimal clinical engagement. If participants could not be engaged through active outreach efforts or declined all participation, they were not pursued further. The result of these treatment compliance definitional criteria, participants attended 12 or more sessions (compliers, $n=60$ ) or 3 or fewer sessions (noncompliers, $n=39 ; M=0.67$, mode $=0$ ), thereby provided the strongest CACE estimates (Connell, 2009). The compliance rate (adjusted for the covariates shown in Figure 1) was $61.7 \%$ based on the estimated posterior probabilities with the BDI-II data and $61.9 \%$ with the HRSD-II data. Table 2 presents covariates predicting the complier group. Overall, none of the examined covariates was significantly related to the ECS groups (class membership).

Figure $2 \mathrm{a}$ and $\mathrm{b}$ present the treatment effects of the IPT (29) versus the ECS $(62 \% \times 29=18)$ using the CACE modeling framework 2 . Trauma symptoms were used as a covariate in the analyses. In CACE analyses, the compliers in the control group are unobserved and are estimated based on the probability of compliance in the treatment group, as well as based on information coming from covariates in the analyses (e.g., demographics). The compliance rate in the control group is expected to be equal to that in the IPT group (by virtue of randomization). Thus, given that the observed probability for compliance in the IPT group was $0.606(60 /$

Table 1. Between group differences in baseline demographic, depression, and trauma variables

\begin{tabular}{|c|c|c|c|c|c|}
\hline & \multicolumn{2}{|c|}{$\begin{array}{l}\text { Assigned to IPT } \\
\text { Treatment }(n=99)\end{array}$} & \multicolumn{2}{|c|}{$\operatorname{ECS}(n=29)$} & \multirow{2}{*}{$\frac{\text { Statistic Test }(d f)}{\chi^{2}}$} \\
\hline & $N$ & $\%$ & $N$ & $\%$ & \\
\hline Married & 11 & 11.1 & 5 & 17.2 & $0.771(1), p=.380$ \\
\hline Maternal education (\% high school) & 58 & 58.6 & 16 & 55.2 & $0.107(1), p=.743$ \\
\hline Race & & & & & $3.302(2), p=.192$ \\
\hline Black & 63 & 63.6 & 13 & 44.8 & \\
\hline White & 34 & 34.3 & 15 & 51.7 & \\
\hline Other & 2 & 2 & 1 & 3.4 & \\
\hline \multicolumn{6}{|l|}{ Ethnicity } \\
\hline Hispanic & 18 & 18.2 & 9 & 31.0 & $2.226(1), p=.136$ \\
\hline \multirow[t]{2}{*}{ CTQ (any maltreatment type) } & 80 & 80.8 & 27 & 93.1 & $2.472(1), p=.116$ \\
\hline & $M$ & $S D$ & $M$ & $S D$ & ANOVA $F(1,128)$ \\
\hline Family income & $18.08 \mathrm{~K}$ & 9.05 & $18.29 \mathrm{~K}$ & 7.51 & $0.012, p=.912$ \\
\hline Maternal age & 25.24 & 4.86 & 25.55 & 5.85 & $0.081, p=.777$ \\
\hline Number of children at home baseline & 2.50 & 1.55 & 2.55 & 1.50 & $0.020, p=.888$ \\
\hline Beck Depression Inventory-II & 30.29 & 8.14 & 30.65 & 10.98 & $0.036, p=.851$ \\
\hline Revised Hamilton Rating Scale for Depression & 15.68 & 7.44 & 17.03 & 6.59 & $0.0761, p=.385$ \\
\hline Trauma experiences & 4.25 & 2.18 & 4.13 & 2.43 & $0.058, p=.811$ \\
\hline
\end{tabular}

Note: IPT, interpersonal psychotherapy; ECS, enhanced community standard; CTQ, childhood Trauma Questionnaire; ANOVA, analysis of variance. 


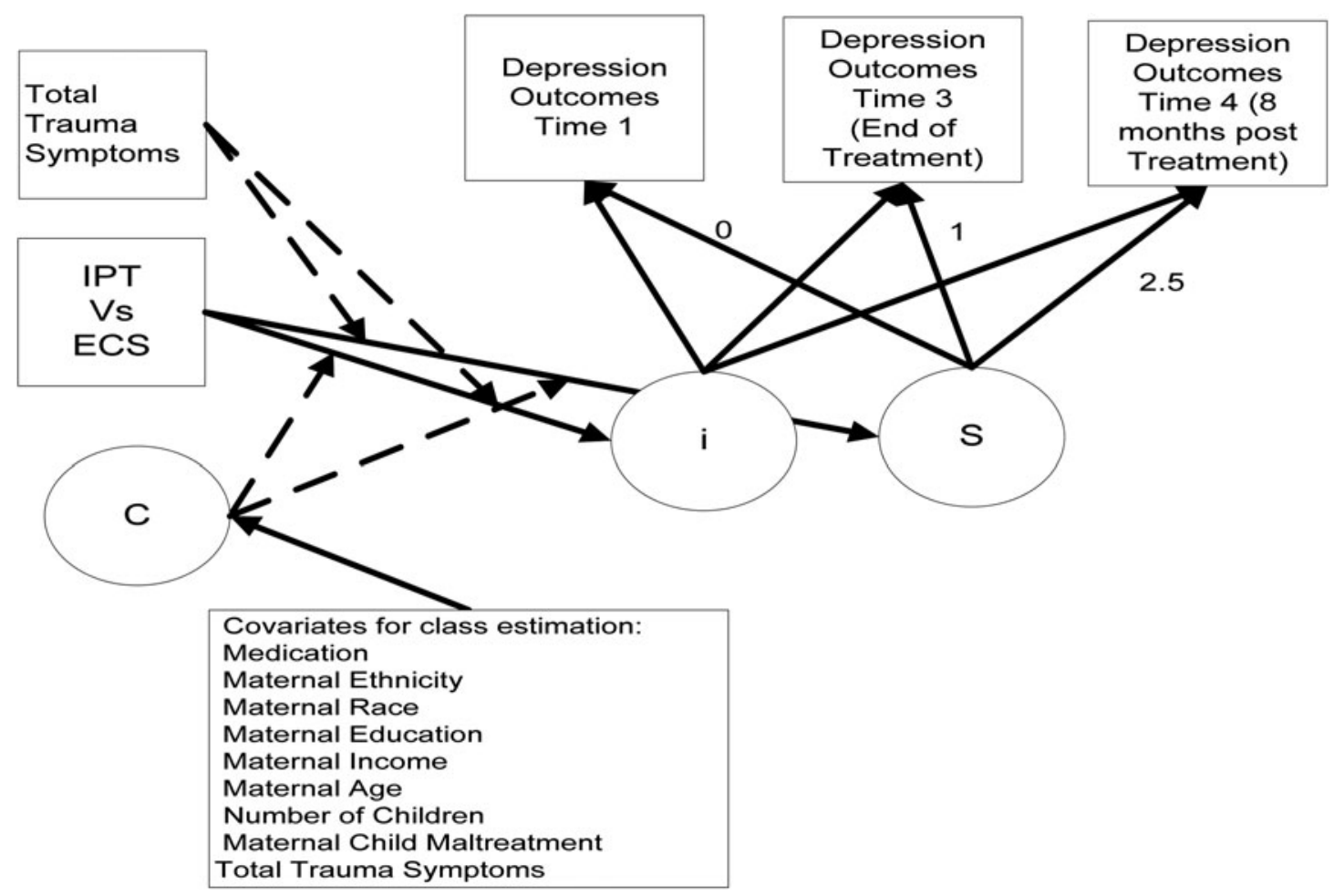

Figure 1. Conceptual model for the CACE modeling. C, Compliance status; IPT, interpersonal psychotherapy; ECS, enhanced community standard.

99), the rate of compliance in the control group was estimated at $60 \%$, resulting in 18 compliers in the ECS group.

Adjusted for noncompliance and with trauma symptoms as a covariate, individuals in the IPT condition experienced significantly greater decreases in depression over time on the BDI-II compared to the ECS condition, $B=-4.483$ (1.602), $t=-2.799, p=.005, d=-0.519$, as well as significantly greater decreases in depression over time as measured by the HRSD-II, $B=-0.538(0.258), t=-2.081, p=.038$, $d=-0.384$. Subsequently, we wanted to test the patterns of efficacy of IPT from baseline to posttreatment. Thus, we also ran two growth curve models ${ }^{1}$ (i.e., BDI and Hamilton) testing the effect of the intervention from pre- (baseline) to postintervention within the CACE modeling framework. Analyses revealed significant reduction in mean depression symptoms among the IPT group compared to the ECS condition. Significant symptom reduction in the IPT group at postintervention was evident on both the HRSD-II and the BDI: HRSD-II, $B=-1.435$ (0.586), $t=-2.45$; BDI, $B=-7.996$ (3.674), $t=-2.177 .^{2}$

1. Residual variances were constrained to zero in order to enable modeling growth between two time points.

2. Auxiliary analyses were conducted outside of the CACE modeling framework in order to ascertain whether the observed IPT treatment group showed significant improvement in depression compared to women in the ECS group who sought counseling in the community (i.e., psychologist, social worker, individual/family counselor or a psychiatrist). Specifically, analyses of covariance (BDI, $F=3.93, d f=1,85, p<.05$; Hamil-
Mediation estimation and analysis of sustained treatment effects

Eight separate models (two depression measures with four mediators) were estimated to assess longitudinal mediation

Table 2. Characteristics predicting the complier group in the Beck Depression Inventory growth model

\begin{tabular}{lrcl}
\hline \hline \multicolumn{1}{c}{ Characteristics } & $\beta$ & $S E$ & $p$ \\
\hline Maternal age & 0.133 & 0.076 & .08 \\
Maternal ethnicity & 0.283 & 0.316 & .873 \\
Maternal race & 0.032 & 0.637 & .417 \\
Number of children & -0.225 & 0.176 & .202 \\
Total CTQ & 0.063 & 0.066 & .347 \\
Total trauma symptoms & -0.062 & 0.108 & .570 \\
Education & 0.806 & 0.506 & .111 \\
Total income & 0.023 & 0.028 & .411 \\
Medication & 0.350 & 0.786 & .656 \\
Anxiety comorbidity & 0.119 & 0.249 & .631 \\
\hline \hline
\end{tabular}

Note: CTQ, Childhood Trauma Questionnaire

ton, $F=8.66, d f=1,85, p<.01)$ confirmed significant depression differences between those receiving IPT compared to the ECS group who received therapy in the community at postintervention. Specifically, the IPT group had significantly lower mean BDI $(M=12.98)$ and Hamilton $(M=10.39)$ scores compared to the ECS group (BDI, $M=19.88$; Hamilton, $M=16.00$ ). 


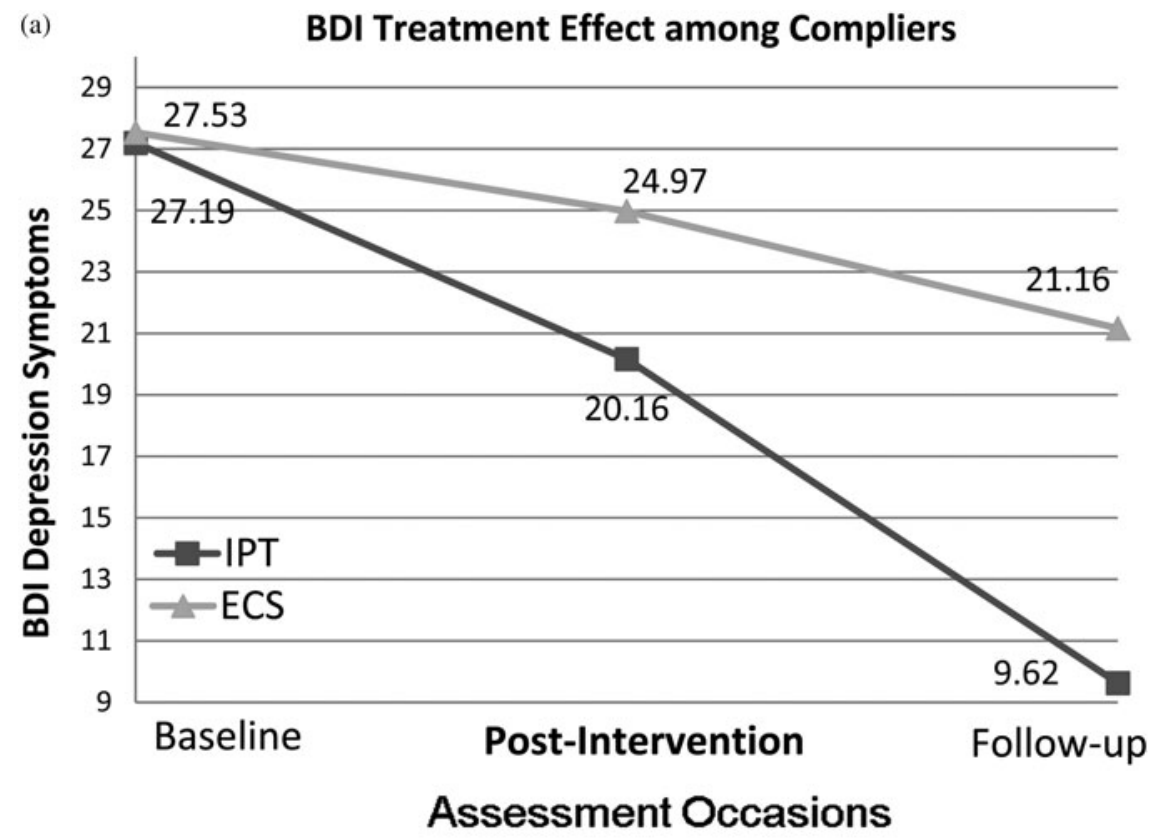

(b) Hamilton Treatment Effect among Compliers

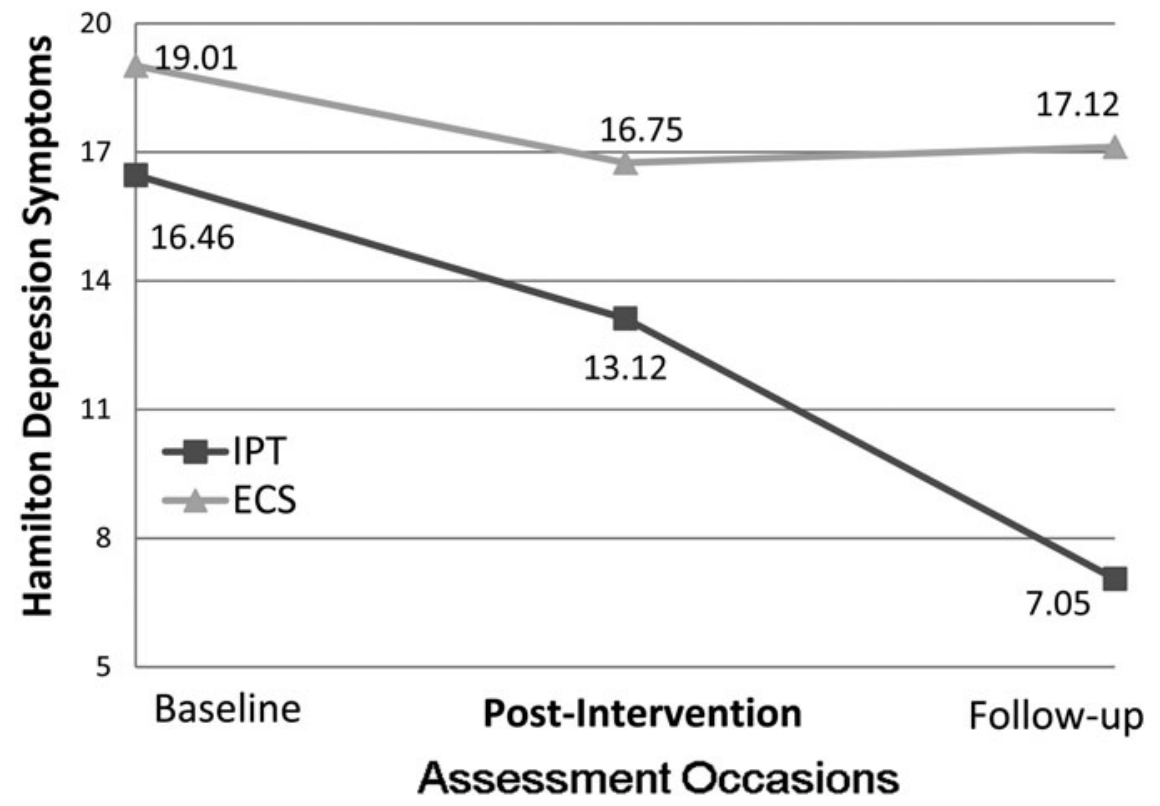

Figure 2. (a) The Beck Depression Inventory-II (BDI) treatment effects and (b) Revised Hamilton Rating Scale for depression treatment effects. IPT, interpersonal psychotherapy; ECS, enhanced community standard.

under the CACE analysis framework. Of these eight models, three had significant effects where (a) IPT significantly predicted change over time in the mediator and (b) change in the mediator predicted depression at the 8-month follow-up. First, in the IPT $\rightarrow$ perceived stress $\rightarrow$ BDI model (i.e., regressing perceived stress on treatment condition and regressing BDI on perceived stress and treatment condition), there were significant changes in perceived stress favoring IPT (i.e., the "a" path), $B=-0.196$ (0.094), $t=-2.078, p=$ $.038, d=0.51$; and changes in perceived stress were related to depression at 8-month follow-up for the "b" path, $B=$
49.809 (8.490), $t=5.782, p<.001, d=0.91$. The correlation between the "a" path and "b" path was 0.257. Incorporating this information into R-Mediation yielded a mediation effect that did not include 0 in the confidence interval $(\mathrm{CI}$; mediated effect $=-9.621, \mathrm{CI}=-0.18651,-0.620$ ). Second, perceived stress also mediated the impact of IPT on the 8month follow-up for depression as measured by the HRSDII (mediated effect $=-5.205, \mathrm{CI}=-8.58,-0.219$ ).

Third, the other mediator that appeared to transmit IPT effects on depression was family social support. Specifically, IPT predicted increases in family social support (compared 
to ECS), "a" path $=0.169$ (0.088), $t=1.925, p=.054, d=$ $0.45)$. Changes in family social support predicted depression at the 8-month follow-up as measured by the HRSD-II, "b" path $=-25.55$ (11.44), $t=-2.233, p=.026, d=0.407$. The correlation between the "a" path and "b" path was 0.618 . The mediation effect did not contain 0 in the $\mathrm{CI}$ (mediated effect $=-4.318, \mathrm{CI}=-7.63,-0.274$ ). Level of friends' social support (SSB-friends) and social adjustment (SASSR) were not found to be statistically significant mediators to the effect of IPT on depression.

\section{Discussion}

The current investigation contributes to the emergent treatment outcome literature that supports the efficacy of IPT for reducing depressive symptoms in economically disadvantaged racially and ethnically diverse women. Moreover, to our knowledge, it is the first RCT to demonstrate the efficacy of IPT for low-income racially and ethnically diverse mothers with infants. Consistent with study hypotheses, women receiving IPT had significantly fewer depressive symptoms postintervention when compared to individuals in the ECS group, and these gains were retained and increased at the 8-month follow-up assessment. Perceived stress and family social support emerged as mediators of sustained treatment efficacy, consistent with study hypotheses. Contrary to expectations, social adjustment and friend's support did not mediate sustained treatment outcome.

The results are congruent with other studies finding that IPT reduces depressive symptoms in mothers with young children (Clark, Tluczek, \& Wenzel, 2003; Grote et al., 2009; O'Hara, Stuart, Gorman, \& Wenzel, 2000). The findings of the current investigation are particularly significant because the women who received and benefitted from the IPT were from a diverse, urban, low-income population and were not seeking treatment despite having clearly elevated depressive symptoms. Rather, they were identified in the community from primary care clinics serving low-income women. Before attempting to actively engage mothers in treatment, they were screened for elevated depressive symptoms and assessed for MDD diagnosis. Given the stigma associated with being diagnosed with a mental disorder and with receiving mental health services in clinic settings among low-income racially and ethnically diverse populations, care was taken to be sensitive to each participant's view of depression, while still providing psychoeducation about depression as a medical illness during treatment. This approach is consistent with cultural adaptations of treatment modules made by others administering IPT to diverse, low-income populations (e.g., Grote et al., 2009). Depression also was framed as a common issue that women with young children frequently experience as a function of the stress associated with childrearing, and challenges associated with living in poverty were discussed in relation to increased stress and depression. Flexibility of service delivery also was of paramount importance. Women were not expected to attend clinic settings, and common barriers related to lack of transportation or child- care were thereby circumvented. Therapists worked with their clients to determine the service delivery venue that would be least stressful, which could include their homes, an area in the community, or even in a small number of instances, sessions in the therapist's car. Therefore approximately $85 \%$ of clients were seen outside of the clinic, with the majority of these sessions occurring in homes. Although it may be challenging to translate the flexible treatment delivery offered in this study into organized mental health care systems, there appear to be important benefits to doing so, as indicated by $100 \%$ of women who engaged in IPT $(n=60)$ receiving the full dose of treatment (i.e., 12-14 sessions).

It is also notable that IPT was effective in treating MDD in a population with multiple risk factors in addition to depression. Over $86.7 \%$ of the women receiving IPT had significant histories of childhood maltreatment, $93.3 \%$ had experienced at least one lifetime traumatic event, and $26.7 \%$ met lifetime criteria for posttraumatic stress disorder. A history of trauma has consistently been shown to contribute to an increased risk for the emergence of MDD (Chapman et al., 2004; Cicchetti \& Toth, 2000), and lifetime rates of MDD have ranged from $13 \%$ to $64 \%$ in women with histories of abuse (Weiss, Longhurst, \& Mazure, 1999). Individuals with early adverse experiences also are more likely to develop depression when confronted with acute stressors than are women with no abuse histories (Hammen, Henry, \& Daley, 2000; Harkness, Bruce, \& Lumley, 2006; Kendler, Kuhn, \& Prescott, 2004). Thus, IPT was effective not only in treating MDD but also in treating MDD in women with significant past and more recent histories of trauma. Because trauma is a major contributor to depression, the availability of treatments that can be utilized with traumatized populations is critical. Our results support the utilization of relational forms of therapy, such as IPT, for depressed women with significant past and current relationship impairments, including histories of maltreatment. This finding is consistent with emergent literature suggesting that cognitive approaches to intervention may be less effective with individuals with trauma histories (Lewis et al., 2010). Future research should investigate the potential differential efficacy of these two treatment models, particularly in racially and ethnically diverse populations with histories of trauma.

In addition to this study's demonstration of the efficacy of IPT in reducing depressive symptoms and in maintaining positive treatment outcomes 8 months posttreatment, the identification of mediators of sustained treatment effects also advances the treatment outcome literature. In the current investigation, perceptions of stress significantly decreased for women who received IPT compared to controls, and this change significantly mediated sustained posttreatment improvements in depression symptoms. Techniques such as problem solving that are utilized in IPT, while focusing on interpersonal issues, may have increased participants' preparedness to cope with daily stressors, thus leading to the alleviation of their depressive symptoms over time.

Perceived social support also emerged as a significant mediator for the posttreatment outcome effect. Because research 
has demonstrated that the representational models of self and other are adversely affected by child maltreatment (Toth, Maughan, Manly, Spagnola, \& Cicchetti, 2002), the ability of IPT to decrease depressive symptoms by increasing perceptions of the availability of social support within the family is particularly compelling. One of the core theoretical foundations of IPT is derived from attachment theory (Stuart \& Robertson, 2003), because it provides the base for formulating how individuals develop, maintain, and end relationships and the framework for conceptualizing how early experiences affect current functioning (Bowlby, 1969, 1977). Although IPT does not attempt to modify an individual's attachment organization, it does address the ways that individuals communicate their attachment needs and how they can do so to facilitate the development of more supportive relationships. It appears that one pathway by which IPT may reduce depressive symptoms in women is by fostering their belief in their ability to obtain desired support from family members.

Contrary to expectations, social adjustment did not emerge as a mediator of sustained treatment outcome. Social adjustment assesses an individual's level of adaptation to and satisfaction with her social environment (Weissman, Sholomskas, \& John, 1981). Given the myriad challenges present in the social environment of these women, it may be counterproductive for them to adapt to and express satisfaction with contexts that, in many ways, are dysfunctional. Rather, continuing to retain the perception that aspects of their environments are maladaptive, particularly given their decreases in perceived stress and increases in perceived social support, may ultimately help them to seek out more adaptive living situations. Alternatively, it is possible that participants may have experienced improvement in one or more role areas (e.g., parental role) that may be related to treatment outcome, but overall changes in social adjustment did not mediate treatment effects. Finally, it is also possible that after depression has abated for a significant period of time, only then will improvements in social adjustment become evident.

Child functioning was not the focus of the current study, but prior research has consistently identified maternal depression as a risk factor for adverse child outcome (Cicchetti \& Toth, 1998; Goodman \& Gottib, 2002). A recent longitudinal study found that improvements in maternal depressive symptoms mediated reductions in child behavior problems (Shaw et al., 2009). Therefore, the ability to treat depression effectively in a group of mothers who are struggling with multiple stressors also possesses important implication not only for the women but also for their children. The intervention provided in the current investigation occurred during the toddler period, when basic cognitive, social, and emotional competencies are developing. This developmental period has been highlighted as a sensitive time for the development of a depressotypic organization (Cicchetti \& Toth, 1998). Accordingly, intervening with mothers when their children are toddlers may be especially useful in altering the negative developmental cascade that can commence with early exposure to maternal depression (Masten \& Cicchetti, 2010) and that can lead to the intergenerational transmission of depression. The outcomes of this intervention for children will be evaluated and reported in future publications.

Although the current investigation contributes to the evidence base for the utilization of IPT with low-income ethnically and racially diverse women with young children, a number of limitations must be noted. Despite the flexible and creative service delivery model utilized, a high percentage of women randomly assigned to IPT declined to participate in the intervention, necessitating an analytic strategy (i.e., the CACE modeling) that could account for this problem. In the ideal world of RCT trials, adherence to randomization condition occurs more smoothly. However, the probability of this occurring is much less likely in a non-treatment-seeking group of high-risk women. Thus, the current investigation offers more feasible ways of conducting RCTs, particularly with high-risk non-treatment-seeking populations. By utilizing alternate strategies for dealing with randomization difficulties, the current study exemplifies how state-of-the-art methodological techniques can be used to overcome common challenges in clinical trials. In addition, although as randomized the sample size would have been a significant advance over many RCTs, because a significant number of women randomized to IPT chose not to receive treatment, it resulted in a smaller than expected number of participants. However, even with this limitation, we were able to demonstrate the sustained efficacy of IPT. As previously stated, the stigma associated with receiving mental health treatment could have been a barrier to some women accepting IPT services. We could also speculate that some women declined treatment because they were not in a "stage of change" and therefore not ready to address the interpersonal contributors to their depression. Perhaps in future studies, adding motivational interviewing techniques to the initial phase of treatment could enhance the engagement process and lead to more clients accepting services. Motivational interviewing is a collaborative, person-centered form of guiding to elicit and strengthen motivation for change (Miller \& Rollnick, 2009). These strategies, if utilized in the beginning of treatment, might enhance the therapeutic relationship and help build rapport with the client, who then may be better able to engage in the therapeutic process. Finally, because participants were not randomly assigned to levels of the mediators, it is not possible to infer causality concerning the effect of the mediators on the outcome. However, we believe that theory and prior research support the assumption that it is less plausible that a decrease in depression could lead to an increase in perceived social support than it is that increased perceived social support could lead to a decrease in depression.

Several important strengths of this investigation must also be noted. RCTs have been criticized for their use of participants more advantaged than those seen in clinical practice (Persons \& Silberschatz, 1998). This study's focus on economically disadvantaged racially and ethnically diverse women struggling with MDD in the context of co-occurring risk factors, including a high prevalence of trauma and co- 
morbid diagnoses, makes the results of this study applicable to clinicians seeing patients in nonresearch settings. Another criticism of RCTs is that they often do not answer pertinent questions regarding how treatment works (Persons \& Silberschatz, 1998). A notable strength of the current research is the identification of perceived stress and perceived social support as mediators of sustained treatment effects. We have elucidated pathways through which IPT is successful in treating depression, which may inform future efforts to improve this already efficacious treatment or reduce treatment time. This study provides a foundation for future research on IPT that can evaluate whether changes to IPT aimed specifically at improving social support and reducing stress improve the efficacy of this treatment, a rigorous test of whether the mediators

\section{References}

American Psychiatric Association. (1994). Diagnostic and statistical manual of mental disorders (4th ed.). Washington, DC: Author.

Bagby, R. M., Ryder, A. G., Schuller, D. R., \& Marshall, M. B. (2004). The Hamilton Depression Rating Scale: Has the gold standard become a lead weight? American Journal of Psychiatry, 161, 2163-2177.

Bateman, B., \& Fonagy, P. (1999). Effectiveness of partial hospitalization in the treatment of borderline personality disorder: A randomized controlled trial. American Journal of Psychiatry, 156, 1563-1569.

Beck, A. T., Steer, R. A., \& Brown, G. K. (1996). Manual for the Beck Depression Inventory - II. San Antonio, TX: Psychological Corporation.

Bernstein, D. P., \& Fink, L. (1994). Childhood Trauma Questionnaire: A retrospective self-report manual. New York: Psychological Corporation.

Bernstein, D. P., Stein, J. A., Newcomb, M. D., Walker, E., Pogge, D., Ahluvalia, T., et al. (2003). Development and validation of a brief screening version of the Childhood Trauma Questionnaire. Child Abuse \& Neglect, 27, 169-190.

Bowlby, J. (1969). Attachment and loss: Vol. 1. Attachment. London: Hogarth Press.

Bowlby, J. (1977). The making and breaking of affectional bonds: 1. Aetiology and psychopathology in the light of attachment theory. British Journal of Psychiatry, 130, 201-210.

Chapman, D. P., Whitfield, C. L., Felitti, V. J., Dube, S. R., Edwards, V. J., \& Anda, R. F. (2004). Adverse childhood experiences and the risk of depressive disorders in adulthood. Journal of Affective Disorders, 82, $217-225$.

Cheong, J., MacKinnon, D. P., \& Khoo, S. T. (2001). A latent growth modeling approach to mediation analysis. In L. M. Collins \& A. Sayer (Eds.), New methods for the analysis of change (pp. 390-392). Washington, DC: American Psychological Association.

Cheong, J., MacKinnon, D. P., \& Khoo, S. T. (2003). Investigation of mediational processes using parallel process latent growth curve modeling. Structural Equation Modeling, 10, 238-262.

Cicchetti, D., \& Toth, S. L. (1998). The development of depression in children and adolescents. American Psychologist, 53, 221-241.

Cicchetti, D., \& Toth, S. L. (2000). Developmental processes in maltreated children. In D. Hansen (Ed.), Nebraska Symposium on Motivation: Child maltreatment (pp. 85-160). Lincoln, NE: University of Nebraska Press.

Clark, R., Tluczek, A., \& Wenzel, A. (2003). Psychotherapy for postpartum depression: A preliminary report. American Journal of Orthopsychiatry, $73,441-454$.

Cohen, S., Kamarck, T., \& Marmelstein, R. (1983). A global measure of perceived stress. Journal of Health and Social Behavior, 24, 385-396.

Connell, A. (2009). Employing complier average causal effect analytic methods to examine effects of randomized encouragement trials. American Journal of Drug and Alcohol Abuse, 35, 253-259.

Cuijpers, P., Geraedts, A. S., van Oppen, P., Andersson, G., Markowitz, J. C., \& van Straten, A. (2011). Interpersonal psychotherapy for depression: A meta-analysis. American Journal of Psychiatry, 168, 581-592.

Dozois, D. J. A., Dobson, K. S., \& Ahnberg, J. L. (1998). A psychometric evaluation of the Beck Depression Inventory-II. Psychological Assessment, 10, 83-89. of sustained posttreatment improvements identified in this study are operating as mechanisms (Kraemer et al., 2002).

In summary, the current investigation demonstrated the efficacy of IPT for decreasing depression in low-income racially and ethnically diverse women with young children. Moreover, the effects of the intervention were maintained 8 months postintervention, and perceived social support and perceived stress were identified as significant mediators of sustained treatment outcome. That the treatment was efficacious in a population of women with extensive trauma histories also advances the literature on the efficacy of IPT. These findings contribute to the evidence base for IPT with diverse populations and underscore the criticality of continuing to address the reluctance of low-income and minority populations to obtain mental health services.

Elkin, I., Shea, M. T., Watkins, J. T., Imber, S. D., Sotsky, S. M., Collins, J. F., et al. (1989). National Institute of Mental Health Treatment of Depression Collaborative. Archives of General Psychiatry, 46, 971-982.

Frank, E., Kupfer, D. J., Perel, J. M., Cornes, C., Jarrett, D. B., Mallinger, A., et al. (1990). Three-year outcomes for maintenance therapies in recurrent depression. Archives of General Psychiatry, 47, 1093-1099.

Goodman, S. H., \& Gotlib, I. H. (Eds.) (2002). Children of depressed parents: Alternative pathways to risk for psychopathology. Washington, DC: American Psychological Association Press.

Gravener, J. A., Rogosch, F. A., Oshri, A., Narayan, A., Cicchetti, D., \& Toth, S. L. (2011). The relations among maternal depressive disorder, maternal expressed emotion, and toddler behavior problems and attachment. Journal of Abnormal Child Psychology. Advance online publication. doi:10.1007/s10802-011-9598-Z

Grote, N. K., Swartz, H. A., Geibel, S. L., Zuckoff, A., Houck, P. R., \& Frank, E. (2009). A randomized controlled trial of culturally relevant, brief interpersonal psychotherapy for perinatal depression. Psychiatric Services, 60, 313-321.

Gunlicks-Stoessel, M., Mufson, L., Jekal, A., \& Turner, B. (2010). The impact of perceived interpersonal functioning on treatment for adolescent depression: IPT-A versus treatment as usual in school-based health clinics. Journal of Consulting and Clinical Psychology, 78, 260-267.

Hammen, C., \& Brennan, P. A. (2003). Severity, chronicity, and timing of maternal depression and risk for adolescent offspring diagnoses in a community sample. Archives of General Psychiatry, 60, 253-258.

Hammen, C., Henry, R., \& Daley, S. E. (2000). Depression and sensitization to stressors among young women as a function of childhood adversity. Journal of Consulting and Clinical Psychology, 68, 782-787. doi:10.1037/ 0022-006X.68.5.782

Harkness, K. L., Bruce, A. E., \& Lumely, M. N. (2006). The role of childhood abuse and neglect in the sensitization to stressful life events in adolescent depression. Journal of Abnormal Psychology, 115, 730-741.

Hobfoll, S. E., Ritter, C., Lavin, J., Hulsizer, M. R., \& Cameron, R. P. (1995). Depression prevalence and incidence among inner-city pregnant and postpartum women. Journal of Consulting and Clinical Psychology, $63,445-453$

Hollon, S. D., DeRubeis, R. J., \& Seligman, M. E. P. (1992). Cognitive therapy and the prevention of depression. Applied and Preventive Psychology, 1, 89-95. doi:10.1016/S0962-1849(05)80149-0

Hollon, S. D., \& Ponniah, K. (2010). A review of empirically supported psychological therapies for mood disorders in adults. Depression and Anxiety, 27, 891-932. doi:10.1002/da.20741

Hyman, S. M., Garcia, M., Kemp, K., Mazure, C., \& Sinha, R. (2005). A gender specific psychometric analysis of the early trauma inventory short form in cocaine dependent adults. Addictive Behaviors, 30, 847-852.

Jo, B. (2002). Estimation of intervention effects with noncompliance: Alternative model specifications. Journal of Educational and Behavioral Statistics, 27, 385-409.

Jo, B. (2008a). Bias mechanisms in intention-to-treat analysis with data subject to treatment noncompliance and missing outcomes. Journal of Educational and Behavioral Statistics, 33, 158-185. 
Jo, B. (2008b). Causal inference in randomized experiments with meditational processes. Psychological Methods, 13, 314-336.

Kazdin, A. E. (2007). Mediators and mechanisms of change in psychotherapy research. Annual Review of Clinical Psychology, 3, 1-27. doi:10.1146/ annurev.clinpsy.3.022806.091432

Kendler, K. S., Kuhn, J., \& Prescott, C. A. (2004). The interrelationship of neuroticism, sex, and stressful life events in the prediction of episodes of major depression. American Journal of Psychiatry, 161, 631-636.

Kessler, R. C., Berglund, P., Demler, O., Jin, R., Koretz., D., Merkiangas, K. R., et al. (2003). The epidemiology of major depressive disorder: Results from the National Comorbidity Survey Replication (NCS-R). Journal of the American Medical Association, 289, 3095-3105. doi:10.1001/ jama.289.23.3095

Kessler, R. C., McGonagle, K. A., Nelson, C. B., Hughes, M., Swartz, M., \& Blazer, D. G. (1994). Sex and depression in the National Comorbidity Survey: II. Cohort effects. Journal of Affective Disorders, 30, 15-26.

Kessler, R. C., McGonagle, K. A., Swartz, M., Blazer, D. G., \& Nelson, C. B. (1993). Sex and depression in the National Comorbidity Survey: I. Lifetime prevalence, chronicity and recurrence. Journal of Affective Disorders, 29, 85-96.

Khan, A., Schwartz, K., Kolts, R. L., Ridgway, D., \& Lineberry, C. (2007). Relationship between depression severity entry criteria and antidepressant clinical trial outcomes. Biological Psychiatry, 62, 65-71. doi:10.1016/ j.biopsych.2006.08.036

Klerman, G. L., Weissman, M. M., Rounsaville, B. J., \& Chevron, E. S. (1984). Interpersonal psychotherapy of depression. Northvale, NJ: Jason Aronson.

Kraemer, H. C., Wilson, G. T., Fairburn, C. G., \& Agras, W. S. (2002). Mediators and moderators of treatment effects in randomized clinical trials. Archives of General Psychiatry, 59, 877-883.

Krupnick, J. L., Green, B. L., Stockton, P., Miranda, J., Krause, E., \& Mete, M. (2008). Group interpersonal psychotherapy for low-income women with posttraumatic stress disorder. Psychotherapy Research, 18, 497507.

Leentjens, A. F. G., Verhey, F. R. J., Lousberg, R., Spitsbergen, H., \& Wilmink, F. W. (2000). The validity of the Hamilton and MontgomeryÅsberg depression rating scales as screening and diagnostic tools for depression in Parkinson's disease. International Journal of Geriatric Psychiatry, 15, 644-649.

Lenze, E. J., Dew, M. A., Mazumdar, S., Begley, A. E., Cornes, C., Miller, M. D., et al. (2002). Combined pharmacotherapy and psychotherapy as maintenance treatment for late-life depression: Effects on social adjustment. American Journal of Psychiatry, 159, 466-468.

Lewis, C. C., Simons, A. D., Nguyen, L. J., Murakami, J. L., Reid, M. W., Silva, S. G., et al. (2010). Impact of childhood trauma on treatment outcome in the Treatment for Adolescents With Depression Study (TADS). Journal of the American Academy of Child \& Adolescent Psychiatry, 49, 132-140.

Little, R. J. A., \& Yau, L. (1998). Statistical techniques for analyzing data from prevention trials: Treatment of no-shows using Rubin's causal model. Psychological Methods, 3, 147-159.

Lopez-Pina, J. A., Sanchez-Meca, J., \& Rosa-Alcazar, A. I. (2009). The Hamilton Rating Scale for Depression: A meta-analytic reliability generalization study. International Journal of Clinical and Health Psychology, 9, 143-159.

Mackinnon, D. P. (2008). Introduction to statistical mediation analysis. New York: Erlbaum.

Marchand, J. F., Hock, E., \& Widaman, K. (2002). Mutual relations between mothers' depressive symptoms and hostile-controlling behavior and young children's externalizing and internalizing behavior problems. Parenting: Science and Practice, 2, 335-353.

Markowitz, J. C. (1998). Interpersonal psychotherapy for dysthymic disorder. Washington, DC: American Psychiatric Press.

Martins, C., \& Gaffan, E. A. (2000). Effects of early maternal depression on patterns of infant-mother attachment: A meta-analytic investigation. Journal of Child Psychology and Psychiatry, 41, 737-746.

Masten, A. S., \& Cicchetti, D. (2010). Developmental cascades. Development and Psychopathology, 22, 491-495.

Miller, W. R., \& Rollnick, S. (2009). Ten things that motivational interviewing is not. Behavioural and Cognitive Psychotherapy, 37, 129-140.

Miranda, J., Chung, J. Y., Green, B. L., Krupnick, J., Siddique, M. S., Revicki, D. A., et al. (2003). Treating depression in predominantly low-income young minority women. Journal of the American Medical Association, 290, 57-65.
Mitchell, A. M., Crane, P. A., \& Kim, Y. (2008). Perceived stress in survivors of suicide: Psychometric properties of the perceived stress scale. Research in Nursing \& Health, 31, 576-585. doi:10.1002/nur.20284

Morris, D. W., Rush, A. J., Jain, S., Fava, M., Wisniewski, S. R., Balasubramani, G. K., et al. (2007). Diurnal mood variation in outpatients with major depressive disorder: Implications for DSM-V from an analysis of the Sequenced Treatment Alternatives to Relieve Depression Study data. Journal of Clinical Psychiatry, 68, 1339-1347.

Mufson, L., Dorta, K. P., Wickramaratne, P., Nomura, Y., Olfson, M., \& Weissman, M. M. (2004). A randomized effectiveness trial of interpersonal psychotherapy for depressed adolescents. Archives of General Psychiatry, 61, 577-584.

Mufson, L., Moreau, D., Weissman, M., Wickramaratne, P., Martin, J., \& Samilov, A. (1994). Modification of interpersonal psychotherapy with depressed adolescents (IPT-A): Phase I and II studies. Journal of the American Academy of Child \& Adolescent Psychiatry, 33, 695-705.

Mufson, L., Weissman, M., Moreau, D., \& Garfinkel, R. (1999). Efficacy of interpersonal psychotherapy for depressed adolescents. Archives of General Psychiatry, 56, 573-579.

Muthén, L. K., \& Muthén, B. (1998-2010). Mplus user's guide: Version 6. Los Angeles: Author.

O'Hara, M., \& Swain, A. (1996). Rates and risks of postpartum depression: A meta-analysis. International Review of Psychiatry, 8, 37-55. doi:10.3109/ 09540269609037816

O'Hara, M. W., Stuart, S., Gorman, L. L., \& Wenzel, A. (2000). Efficacy of interpersonal psychotherapy for postpartum depression. Archives of General Psychiatry, 57, 1039-1045.

Persons, J. B., \& Silberschatz, G. (1998). Are results of randomized controlled trials useful to psychotherapists? Journal of Consulting and Clinical Psychology, 66, 126-135.

Persons, J. B., Thase, M. E., \& Crits-Christoph, P. (1996). The role of psychotherapy in the treatment of depression. Archives of General Psychiatry, 53, 283-290.

Pilowsky, D. J., Wickramaratne, P., Talati, A., Tang, M., Hughs, C. W., Garber, J., et al. (2008). Children of depressed mothers 1 year after the initiation of maternal treatment: Findings from the STAR*D-Child study. American Journal of Psychiatry, 165, 1136-1147.

Radloff, L. S. (1977). The CES-D Scale: A self-report depression scale for research in the general population. Applied Psychological Measurement, $1,385-401$.

Regier, D. A., Herschfeld, R. M., Goodwin, F. K., Burke, J. D., Lazar, J. B., \& Judd, L. L. (1988). The NIMH depression awareness, recognition, and treatment program: Structure, aims, and scientific basis. American Journal of Psychiatry, 145, 1351-1357.

Robins, L. N., Cottler, L., Bucholz, K., \& Compton, W. (1995). Diagnostic Interview Schedule for DSM-IV. St. Louis, MO: Washington University Press.

Robins, L. N., Helzer, J. E., Croughan, J., \& Ratcliff, K. S. (1981). National Institute of Mental Health Diagnostic Interview Schedule: Its history, characteristics, and validity. Archives of General Psychiatry, 38, 381-389.

Robins, L. N., Helzer, J. E., Ratcliff, K. S, \& Seyfried, W. (1982). Validity of the Diagnostic Interview Schedule, version II: DSM-III diagnoses. Psychological Medicine, 12, 855-870.

Robins, L. N., Helzer, J. E., Weissman, M. M., Orvaschel, H., Gruenberg, E., Burke, J. D., et al. (1984). Lifetime prevalence of specific psychiatric disorders in three sites. Archives of General Psychiatry, 41, 949-958.

Rossello, J., \& Bernal, G. (1999). The efficacy of cognitive-behavioral and interpersonal treatments for depression in Puerto Rican adolescents. Journal of Consulting and Clinical Psychology, 67, 734-745.

Rossello, J., Bernal, G., \& Rivera-Medina, C. (2008). Individual and group CBT and IPT for Puerto Rican adolescents with depressive symptoms. Cultural Diversity and Ethnic Minority Psychology, 14, 234-245.

Schafer, J. L., \& Graham, J. W. (2002). Missing data: Our view of the state of the art. Psychological Methods, 7, 147-177.

Segre, L. S., O'Hara, M. W., Arndt, S., \& Stuart, S. (2007). The prevalence of postpartum depression: The relative significance of three social status indices. Social Psychiatry and Psychiatric Epidemiology, 42, 316-321. doi: 10.1007/s00127-007-0168-1

Shaw, D. S., Connell, A., Dishion, T. J., Wilson, M. N., \& Gardner, F. (2009) Improvements in maternal depression as a mediator of intervention effects on early childhood problem behavior. Development and Psychopathology, 21, 417-439.

Siefert, K., Bowman, P. J., Heflin, M. P. P., Danziger, S., \& Williams, D. R. (2000). Social and environmental predictors of maternal depression in 
current and recent welfare recipients. American Journal of Orthopsychiatry, 70, 510-522.

Silk, J. S., Shaw, D. S., Forbes, E. E., Lane, T. L., \& Kovacs, M. (2006). Maternal depression and child internalizing: The moderating role of child emotion regulation. Journal of Clinical Child and Adolescent Psychology, 35, 116-126.

Smedley, B. D., Stith, A. Y., \& Nelson, A. R. (2002). Unequal treatment: Confronting racial and ethnic disparities in health care. Institute of Medicine Report. Washington, DC: National Academy Press.

Spinelli, M. G., \& Endicott, J. (2003). Controlled clinical trial of interpersonal psychotherapy versus parenting education program for depressed pregnant women. American Journal of Psychiatry, 160, 555-562.

Storch, E. A., Roberti, J. W., \& Roth, D. A. (2004). Factor structure, concurrent validity, and internal consistency of the Beck Depression Inventory-second edition in a sample of college students. Depression and Anxiety, 19, 187-189. doi:10.1002/da.20002

Stuart, S. (2008). What is IPT? The basic principles and the inevitability of change. Journal of Contemporary Psychotherapy, 38, 1-10. doi:10.1007/ s10879-007-9063-Z

Stuart, S., \& Robertson, M. (2003). Interpersonal psychotherapy: A clinician's guide. London: Edward Arnold.

Tabuse, H., Kalali, A., Azuma, H., Ozaki, N., Iwata, N., Naitoh, H., et al. (2007). The new GRID Hamilton Rating Scale for Depression demonstrates excellent inter-rater reliability for inexperienced and experienced raters before and after training. Psychiatry Research, 153, 61-67.

Talbot, N. L., Conwell, Y., O'Hara, M. W., Stuart, S., Ward, E. A., Gamble, S. A., et al. (2005). Interpersonal psychotherapy for depressed women with sexual abuse histories: A pilot study in a community mental health center. Journal of Nervous and Mental Disease, 193, 847-850.

Tofighi, D., \& MacKinnon, D. P. (2011). RMediation: An R package for mediation analysis confidence intervals. Behavior Research Methods, 43, 692-700.

Toth, S. L., Maughan, A., Manly, J. T., Spagnola, M., \& Cicchetti, D. (2002). The relative efficacy of two interventions in altering maltreated preschool children's representational models: Implications for attachment theory. Development and Psychopathology, 14, 777-808.

Toth, S. L., Rogosch, F. A., Manly, J. T., \& Cicchetti, D. (2006). The efficacy of toddler-parent psychotherapy to reorganize attachment in the young offspring of mothers with major depressive disorder: A randomized preventive trial. Journal of Consulting and Clinical Psychology, 74, 10061016.

Trivedi, M. H., Rush, A. J., Wisniewski, S. R., Nierenberg, A. A., Warden, D., Ritz, L., et al. (2006). Evaluation of outcomes with Citalopram for depression using measurement-based care in $\mathrm{STAR} * \mathrm{D}$ : Implications for clinical practice. American Journal of Psychiatry, 163, 28-40.

US Census Bureau. (2006-2010). Selected Economic Characteristics: American Community Survey. Monroe County, NY. Retrieved September 10, 2012, from http://factfinder2.census.gov/faces/tableservices/jsf/pages/ productview.xhtml?src $=$ bkmk
US Department of Health and Human Services. (2001). Mental health: Culture, race, and ethnicity: A supplement to mental health: A report of the Surgeon General. Rockville, MD: Author.

Vaux, A., \& Harrison, D. (1985). Support network characteristics associated with support satisfaction and perceived support. American Journal of Community Psychology, 13, 245-268.

Vaux, A., Riedel, S., \& Stewart, D. (1987). Modes of social support: The social support behaviors (SS-B) scale. American Journal of Community Psychology, 15, 209-232. doi:10.1007/BF00919279

Vesga-Lopez, O., Blanco, C., Keyes, K., Olfson, M., Grant, B. F., \& Hasin, D. S. (2008). Psychiatric disorders in pregnant and postpartum women in the United States. Archives of General Psychiatry, 65, 805-815.

Wang, P. S., Lane, M., Olfson, M., Pincus, H. A., Wells, K. B., \& Kessler, R. C. (2005). Twelve-month use of mental health services in the United States. Archives of General Psychiatry, 62, 629-640.

Warren, W. L. (1994). Revised Hamilton Rating Scale for Depression (RHRSD): Manual. Los Angeles: Western Psychological Services.

Weiss, E. L., Longhurst, J. G., \& Mazure, C. M. (1999). Childhood sexual abuse as a risk factor for depression in women: Psychosocial and neurobiological correlates. American Journal of Psychiatry, 156, 816-828.

Weissman, M. M. (1999). Social Adjustment Scale-Self-Report (SAS-SR): User's manual. North Tonawanda, NY: Multi-Health Systems.

Weissman, M. M., \& Bothwell, S. (1976). Assessment of social adjustment by patient self-report. Archives of General Psychiatry, 33, 1111-1115.

Weissman, M. M., \& Markowitz, J. C. (1994). Interpersonal psychotherapy. Archives of General Psychiatry, 51, 599-606.

Weissman, M. M., Markowitz, J. W., \& Klerman, G. L. (2000). Comprehensive guide to interpersonal psychotherapy. New York: Basic Books.

Weissman, M. M., \& Olfson, M. (1995). Depression in women: Implications for health care research. Science, 269, 799-801.

Weissman, M. M., Pilowsky, D. J., Wickramarante, P. J., Talati, A., Wisniewski, S. R., Fava, M., et al. (2006). Remissions in maternal depression and child psychopathology: A STAR*D-Child report. Journal of the American Medical Association, 295, 1389-1398.

Weissman, M. M., Sholomskas, D., \& John, K. (1981). The assessment of social adjustment: An update. Archives of General Psychiatry, 38, $1250-1258$.

Weissman, M. M., Wickramaratne, P., Nomura, Y., Warner, V., Pilowsky, D., \& Verdeli, H. (2006). Offspring of depressed parents: 20 years later. American Journal of Psychiatry, 163, 1001-1008.

Whiffen, V. E., \& Gotlib, I. H. (1993). Comparison of postpartum and nonpostpartum depression: Clinical presentation, psychiatric history, and psychosocial functioning. Journal of Consulting and Clinical Psychology, 61, 485-494.

Williams, D. R., \& Collins, C. (1995). U.S. socioeconomic and racial differences in health. Annual Review of Sociology, 21, 349-386.

Yuan, K. H., \& Bentler, P. M. (2000). Robust mean and covariance structure analysis through iteratively reweighted least squares. Psychometrika, 65, 43-58. 